\title{
UMA NOVA MORALIDADE PARA A CIVILIZAÇÃO TECNOLÓGICA?
}

\author{
Antropologia Normativa, Hermenêutica e Responsabilidade ${ }^{1}$
}

\author{
A New Morality to Technological Civilization? \\ Normative Anthropology, Hermeneutics and Responsibility.
}

Maurício Fernandes ${ }^{2}$

\begin{abstract}
Resumo: Adentramos em uma época, definitivamente, sem precedentes. Uma época na qual todas as metanarrativas se esvaziaram normativamente, os exemplos de outrora de tornaram opacos, enquanto transitamos na terra de ninguém, no vazio ético. Os valores, antes encarados como sólidos, se desmancharam no ar, ao passo que os novos valores encarnados pelo novo homem moderno, ainda não despontaram no horizonte. A Modernidade não possui de onde retirar seus exemplos, exceto de si mesma, da tentativa de construir estes novos valores e normatividade. A vida danificada aparece em um horizonte próximo em nossa sociedade, é posta por todos os lados na perspectiva dos sujeitos que, saqueados de seu potencial de emancipação e autonomia, transitam na perspectiva imposta pelo mercado e pelo controle biopolítico dos corpos, e na transformação do sujeito em um mero conjunto de dados (Gläserner Mensch). A única possibilidade de recobrar-se deste cenário é a reabilitação de conteúdos que articulem uma tomada de posicionamento que restitua ao sujeito a possibilidade de projetar uma autobiografia de uma vida não danificada. Esta restituição da autonomia do sujeito, a responsabilidade e a tomada de decisões em cenários práticos implicam em um novo rumo ao quadro de nossa moralidade. É precisamente neste novo rumo que centramos esforços neste texto, no intuito de expor uma problemática complexa, da qual uma possível e necessária resolução seja a construção de uma nova moralidade. Um novo tipo de relação com nosso poder investido pela tecnociência, e nosso existir. Neste contexto há um itinerário marcado por contributos da Hermenêutica que podem ser assumidos na construção desta nova moralidade.
\end{abstract}

Palavras-Chaves: Técnica/tecnologia. Moralidade. Hermenêutica.

Abstract: We have entered an epoch, definitely unprecedented. A time marked by the normative emptiness of all metanarratives, the examples of the past have become opaque as we move into noman's-land, into ethical emptiness. Values, once regarded as solid, melts into the air, while the new values, embodied by the new modern man, have not appeared on the horizon. Modernity has no way of search for examples anywhere, except from itself, from the attempt to construct these new values and normativity. Damaged life appears on a near horizon in our society, is placed on all sides from the perspective of a subject plundered from their potential for emancipation and autonomy, that transit from the perspective imposed by the market and the biopolitical control of bodies, and in the transformation of the subject. In a mere dataset (Gläserner Mensch). The only possibility of recovering from this scenario is the rehabilitation of contents that articulate and restores to the subject the possibility of projecting an autobiography of an undamaged life. This restoration of the

\footnotetext{
${ }^{1}$ Texto apresentado no III Colóquio de Filosofia Hermenêutica: Linguagem e Comunicaşão, realizado entre os dias 22 e 24 de outubro de 2019, na Universidade Federal do Piauí, na cidade de Teresina.

${ }^{2}$ Doutor em Filosofia pela Universidade do Vale do Rio dos Sinos (UNISINOS). Professor permanente do Programa de Pós-Graduação em Filosofia da UFPI. Professor de Filosofia na UFPI. Membro pesquisador no GT Filosofia da Técnica e Tecnologia da ANPOF.
} 
subject's autonomy, responsibility and decision-making in practical scenarios imply a new direction in the framework of our morality. It is precisely in this new direction that we focus our efforts on this text, in order to expose a complex problem, of which a possible and necessary resolution is the construction of a new morality. A new kind of relationship with our power invested by technosciences, and our existence. In this context there is an itinerary marked by contributions from hermeneutics, assumed in the construction of this new morality.

Keywords: Technique / technology. Morality. Hermeneutics.

\section{INTRODUÇÃO}

A técnica tornou-se, já há alguns séculos, o Zeitgeist, para utilizarmos aqui uma expressão de Ferrater-Mora (1947). Um fenômeno constitutivo de nossa espécie, ambíguo e que nos exige reflexões urgentes dado seu avanço sem precedentes nas últimas décadas do século XX e início do século corrente. A técnica, compreendida como técnica moderna ou como tecnologia, se espraia por cada esfera da vida humana, o que corrobora a perspectiva antropológica de nossa tecnicidade formativa: somos seres técnicos.

Em finais do século passado experimentamos, por vez primeira, as frustrações diante dos resultados no nossa ação sobre o mundo, nos posicionamos de frente à danos irreversíveis causados à Natureza; e também diante de uma descida de nossa ação biotécnica à âmbitos recônditos de nossa existência, imprimindo novas exigências de redescrição do mundo e de nós mesmos.

Esta exigência redescricional expressa pela técnica acirra, desde meados da primeira metade do século XX, uma nova compreensão de nosso agir, e por conseguinte, de nossa moralidade. A técnica acirra problemas humanos, problemas que já possuímos em potencial e que são acirrados diante do avanço tecnológico. O que nos leva a assumirmos inicialmente uma compreensão de técnica/tecnologia para além da imagem de uma força demoníaca, sempre a seduzir o homem, que, irresponsavelmente, acredita estar em alguma paisagem paradisíaca pré-reflexiva. A técnica é um fenômeno constitutivo de nossa trajetória evolutiva e obedece à critérios cognitivos e normativos emanados de nossa tessitura social, histórica e cultural, dentre outros; portanto, refletir sobre o fenômeno técnico é refletir sobre nosso próprio agir sobre o mundo e sobre nós mesmos.

Em um primeiro momento, esboçaremos um cenário do século XX e os impactos dos avanços tecnológicos na configuração de uma civilização, já marcadamente tecnológica. Nos deteremos em dois grandes eventos que marcaram, e ainda marcam, o ritmo dos avanços tecnocientíficos e biotecnológicos, estes eventos são: 1) a descoberta da fissão do núcleo atômico, e 2) a clonagem da Ovelha Dolly e o mapeamento do Genoma humano. Apontaremos para s impactos destes avanços na sociedade humana e seus enfrentamentos cautelares por parte até mesmo da própria ciência, e a busca por uma normatividade que dê conta de tais avanços. 
A partir deste cenário, procederemos à uma reflexão sobre a condição de nossa moralidade frente a tais avanços. Possuímos os conteúdos morais necessários à uma estruturação normativa sobre os avanços tecnocientíficos, e principalmente biotécnicos? Ou necessitamos de uma nova moralidade?

E por fim, nos direcionaremos para uma abordagem dos contributos da Hermenêutica a este cenário, procurando apontar que o que está em jogo é a capacidade redescricional dos indivíduos frente ao fenômeno técnico, não se trata da técnica em si, mas do uso que fazemos da mesma e suas consequências no âmbito da sociedade.

\section{UM CENÁRIO MARCADO PELA TÉCNICA/TECNOLOGIA}

Algo facilmente constatável, é o fato de termos adentrado em uma época sem precedentes em relação ao avanço tecnológico, e isto, desde o século XIX, mostra-se em um avanço que marca o ritmo das formas de vida contemporâneas, ao mesmo tempo em que apresenta expressiva diferença em relação aos avanços anteriores. Atualmente, o avanço das tecnociências atingem um grau de penetração cada vez mais profundo nos âmbitos mais recônditos da existência humana.

Os avanços no campo das engenharias genéticas, no campo da robótica, da nanotecnologia e da neurobiologia, imprimem acirradamente uma nova forma de interpretação do mundo e de nós mesmos; imprimem também uma exigência muito forte de redescrição daquilo que nós somos e do que fazemos com/do o mundo.

É uma época também marcada pelo esvaziamento normativo das metanarrativas, que já não oferecem respostas a nova forma de vida surgida na Modernidade. Os exemplos, que outrora eram vividos na constituição e tessitura do próprio ethos das sociedades humanas, hoje se tornaram opacos e esvaziaram-se. Utilizando uma imagem jonasiana, passamos a transitar a terra de ninguém ou um ambiente marcado pelo esvaziamento ético (JONAS, 1984).

Seguindo o diagnóstico de Marx sobre a Modernidade, os valores, antes encarados como sólidos, se desmancharam no ar, ao passo que os novos valores encarnados pelo novo homem ainda não despontaram no horizonte, todas as metanarrativas, todos os conteúdos normativos que antes pensávamos ou acreditávamos serem inabaláveis se desmancharam abruptamente.

Ernst Jünger afirma que que o sentimento corrente é de que os valores que antes eram sólidos se tornaram caducos na Modernidade, sem aparecer de fato no horizonte da mesma, os novos valores preconizados pelo homem moderno. A modernidade não consegue retirar seus exemplos e lugar algum, não há mais exemplos possíveis a serem seguidos, a vida dos santos não representa mais que uma forma arcaica e caduca, longe de ser um exemplo a ser seguido pelo 
homem moderno, não há mais exemplos possíveis. Neste sentido, a modernidade deve buscar construir esses novos valores e normatividade a partir de si mesma.

A vida danificada aparece no horizonte próximo da sociedade, é colocada por todos os lados na perspectiva de sujeitos saqueados de seu potencial de emancipação e autonomia, na perspectiva imposta pelo mercado e pelo controle biopolítico dos corpos, na transformação gradual do sujeito em um conjunto de dados (Gläserner Mensch). Nesse sentido, este cenário da contemporaneidade, é marcado por uma crise muito forte. Ela atinge um patamar acirrado em finais do século XX com todos os avanços que a tecnologia imprimiu em nossa forma de conhecer e agir sobre o mundo.

O cenário que aqui descrevemos é marcado fortemente por uma crise que atinge século XX e início do Século XXI, como um acirramento das forças de reificação e de destruição devido ao avanço das intervenções tecnológicas sobre o mundo e sobre o próprio humano. Neste cenário apontamos dois eventos importantes que ocorreram no século XX e que vão impactar a forma como tratamos com o conhecimento científico, em seus usos e potencialidades inerentes.

O primeiro evento nos aponta a necessidade de responsabilidade, o conhecimento não é algo que transita sem critérios ou normas. E neste sentido, envolve responsabilidade. Assim, em 1938 ocorre a descoberta da fissão do núcleo atômico pelo pelos físicos Otto Hahn e Fritz Strassman, fato que inaugura um novo horizonte para a pesquisa científica, abrindo caminho para a pesquisa nuclear (MAX-PLANK-GESELLSHAFT, 2018).

Alguns anos após a descoberta, Robert Oppenheimer que passou a trabalhar em uma base militar em Los Álamos, construindo as primeiras ogivas nucleares. As quais foram imediatamente lançadas sobre duas cidades japonesas - Hiroshima e Nagasaki, pelo poder político norteamericano; o que levou Robert Oppenheimer a uma depressão, a pensar sobre a sua responsabilidade sobre a morte de milhares a partir de suas experiências, Otto Hahn também entrou em depressão após os usos políticos e militares de sua descoberta.

Este é momento expressivo no qual o nosso conhecimento chega a um patamar no qual conseguimos desenvolver um tipo de ação sobre o mundo que trouxe consigo uma verdadeira hecatombe, que desencadeou as forças titânicas da técnica, como apontavam os irmãos Jünger (Ernst Jünger e Georg Jünger).

A duas cidades japonesas foram devastadas e o potencial destrutivo da bomba atômica era enorme para época, o que desencadeou entre os próprios físicos uma busca por freios ou por condições que permitissem a tomada de responsabilidade por parte dos próprios cientistas sobre o que estavam produzindo; inclusive foi criado logo após o Instituto Max-Planck de Investigação sobre as Condições de Vida no Mundo Técnico e Cientifico [Max-Planck-Institut zur Erforschung der Lebensbedingungen 
der wissenschaftlich-technischen Welt], que será assumido em 1971 na sua direção por Jürgen Habermas (PIZZI, 1996).

Um evento de importância entre os dois que pretendemos descrever aqui, e que também expressa muito da relação que possuímos com o conhecimento e impacta na forma também como nos portamos diante da pesquisa científica foi, sem dúvida, o advento dos campos de concentração nazistas. Nos quais aproximadamente seis milhões de judeus foram exterminados. Estes campos foram transformados em verdadeiros celeiros para as experiências nefastas e macabras de determinados médicos que realizavam suas experiências com seres humanos vivos; experiências das mais bizarras como as trocas de membros, experiências com cérebro humano, experiências com os limites da dor, com os limites fome, com a injeção de substâncias nocivas no corpo das vítimas, tais experiências mostraram qual os limites do conhecimento.

O conhecimento por si só se justifica? Este é um tipo de reflexão que vai ser expresso no período do pós-guerra, quando serão abertas sessões de cinema para mostrarem aos alemães os horrores dos campos de concentração, sessões estas nas quais muitos não conseguiram permanecer assistindo. Os horrores dos campos de concentração foram levados ao Tribunal de Nuremberg e se constituíram como impulso primeiro na construção de uma rede de proteção ao participante de qualquer pesquisa científica, estabelecendo assim, as bases e os primeiros estímulos num quadro teórico para a constituição da bioética contemporânea (CLOTET, 2012).

O outro evento expressivo ao qual nos remetemos, que marca, mais precisamente o final do século XX e início do século XXI, é a descoberta da estrutura da dupla hélice do DNA por Watson e Crick. Embora as pesquisas que vão fornecer as bases para esse desenvolvimento tenham também sido iniciadas na década de 1930 por Warren e Waver ao realizarem uma descida radical da Biologia a uma Química dos genes, será na década de 1950 que Watson e Crick terão os elementos necessários para apresentar ao público acadêmico e a sociedade em geral a estrutura da dupla hélice do DNA.

A partir desta exposição, as pesquisas no campo da genética terão um avanço significativo, e em 1973 é anunciado o primeiro DNA recombinante. As pesquisas neste campo terão impacto expressivo com a clonagem da ovelha Dolly na década de 1990, sendo o primeiro mamífero clonado a partir de uma célula adulta, e outro fato, paralelo à clonagem da ovelha Dolly, foi o início do projeto para mapeamento do genoma humano (Projeto Genoma).

Esses dois eventos que marcaram o ritmo dos avanços no século XX, ocasionaram uma efervescência no ambiente intelectual no momento em que eles se relacionam no sentido de mostrar que agora é possível interferirmos na nossa própria constituição genética, ou seja, em finais do século XX, não apenas imprimimos uma alteração massiva sobre o mundo tal qual o 
conhecemos, mas agora a tecnologia provê os meios de adentrarmos cada vez mais nos âmbitos mais recônditos da nossa estrutura genética. Isto fez soar o alarme a partir do qual muitos intelectuais e inclusive os próprios cientistas envolvidos nestas pesquisas e práticas serão os primeiros a tentar construir barreiras normativas para o uso dessas técnicas em contextos puramente humanos. Como aponta o embriologista que coordenou a clonagem da ovelha Dolly, Ian Wilmut em entrevista:

\footnotetext{
Estamos conscientes de que há potencial para uso indevido e fornecemos informações aos especialistas em ética e à Autoridade de Embriologia Humana. Acreditamos que é importante que a sociedade decida como queremos usar essa tecnologia e garantimos que ela proíba o que deseja proibir. Seria desesperadamente triste se as pessoas começassem a usar esse tipo de tecnologia com as pessoas (WILMUT Apud KOLATA, 1997).
}

A compreensão derrotista acerca da possibilidade de construção de respostas satisfatórias ao problema das ameaças à natureza humana frente aos avanços das biotécnicas encaminhou-se para uma busca de critérios dentro da própria ciência, como a busca de elementos dentro da própria biologia, que impossibilitariam a clonagem humana. Mas como aponta Habermas (2004), apesar de toda a efervescência acerca da dissolução das fronteiras entre natureza humana e biotécnicas, não conseguiram frear o avanço desta última sobre aquela.

No início do século XXI duas formas biotécnicas apresentam uma evolução ímpar que, de um lado, nos maravilha, e de outro, nos enche de espanto e incertezas, a saber: a CRISPR cas9 e a Prime Editing. Elas imprimem uma nova forma de interpretação e redescrição do mundo, tal qual estamos vivenciando.

\section{UM HORIZONTE REDESCRICIONAL}

Como uma forma de esboçar este cenário, marcado pela tecnologia e pela biotécnica, devemos compreender que a tecnologia, neste marco temporal, imprime um caráter de acirramento das exigências de reflexão e racionalização que se abateram sobre o ocidente na Modernidade. As sociedades humanas são marcadas por um processo de racionalização, no qual ondas reflexivas se abatem sobre tais sociedades exigindo a construção de novas imagens, redescrições e interpretações de a sua própria condição e de sua forma de ação no mundo.

Neste sentido, são apresentadas novas perspectivas, novas possibilidades; é um momento de ajuste das formas de vida das sociedades com o novo horizonte redescricional impresso pelas exigências de racionalização. Porém, a partir da modernidade estas ondas reflexivas se abateram de forma intensa sem, no entanto, prover um tempo necessário para sedimentação de conteúdos específicos que pudessem ainda fornecer estímulos ou ajudar a sociedade a se reestruturar frente 
aos impactos redescricionais da tecnologia. Vivemos hoje a crista de uma onda reflexiva que caracteriza uma das maiores crises nas quais a sociedade ocidental atravessa. Esta crise no fornecimento de respostas impacta de modo abarcante todos os modos de reprodução das sociedades ocidentais e as suas formas de vida cotidianas. Neste sentido, a moralidade será colocada em xeque, serão apresentados seus limites diante do avanço tecnocientífico.

Devemos ter em consideração uma afirmação do biólogo e entomologista Eduardo Osborne Wilson que irá apontar o problema que vivenciamos atualmente nos seguintes termos:

\footnotetext{
Creio que estamos prontos para criar um sistema de crenças mais centrado no ser humano. Eu percebo que pareço um defensor da ciência e da tecnologia, e talvez eu seja porque estamos agora em uma era tecnocientífica. Não vejo saída dos problemas que a religião organizada e o tribalismo criam além dos humanos, apenas se tornando mais honestos e plenamente conscientes de si mesmos. No momento, estamos vivendo no que Carl Sagan corretamente denominou um mundo assombrado por demônios. Criamos uma civilização de Guerra nas Estrelas, mas temos emoções paleolíticas, instituições medievais e tecnologia divina. Isso é perigoso. (WILSON, 2012).
}

Chama-nos a atenção essa primeira afirmação de Wilson: possuímos emoções pré-bistóricas, no lugar de emoções, podemos compreender uma moralidade pré-histórica, possuímos uma moralidade paleolítica, uma moralidade que possui seus conteúdos fundamentais construídos em um período totalmente diferente do mundo atual; por exemplo, os conteúdos da nossa moralidade como a solidariedade, colocar-se no lugar do outro, respeito mútuo, etc., foram construídos durante um período em que nos estruturávamos como uma sociedade de caçadores-coletores. Neste período, estes elementos serão estimulados no intuito de que o grupo pudesse sobreviver, e nesse sentido, é um momento em que se constroem os primeiros alicerces da moralidade humana.

Logicamente, esses conteúdos não estão prontos, nem dados de forma fixa no mundo, serão desenvolvidos, serão forjados em um ambiente marcado por uma população em torno de 5 milhões de homo sapiens, ao passo que atualmente trabalhamos com os mesmos conteúdos morais com uma população que já se aproxima da marca de 10 bilhões. A partir destes dados, podemos compreender a desorientação e o esvaziamento moral que a nossa sociedade atual atravessa, sendo impactada de forma acirrada. Por exemplo, os países da Europa são marcadamente arraigados dentro de uma tradição moral cristã, são também países que protagonizam o rechaço aos imigrantes, com índices elevados de xenofobia. Nesse sentido, qual o problema que está ocorrendo?

Transitamos em um cenário em que esses conteúdos morais, construídos quando ainda éramos uma sociedade de caçadores-coletores, não suportam as formas de vida e os modos de reprodução da sociedade contemporânea. A tecnologia apenas acirrou problemas que já vinham sendo evidenciados em cada uma das ondas que se se abatiam sobre a sociedade ocidental. Nesse 
sentido, com a modernidade e, principalmente a partir da Revolução Industrial, com o advento da mercadoria, é desvelado o ambiente problemático acirrado pelos avanços da tecnologia atrelada à ciência moderna.

A moralidade não conseguiu avanços significativos, por isto, o diagnóstico tecido por Hans Jonas, no qual parece que a ética e a tecnologia transitam em direções totalmente opostas, à tal ponto que, a cada avanço da tecnologia, há um posicionamento estático da ética, que permanece pensando conteúdos para uma sociedade presente. Por isso Jonas vai construir um princípio ético que não se aplique apenas à comunidade presente na sociedade, mas a uma comunidade futura, estando relacionada às novas gerações. O princípio ético Jonasiano, é direcionado as gerações futuras, a uma comunidade que ainda não existe e, nesse sentido, os avanços da tecnologia irão imprimir uma retomada do conceito de responsabilidade, que permeará grande parte das propostas éticas do século XX. Muitos intelectuais tentarão reconstruir um padrão ético tendo como prisma básico o conceito de responsabilidade, que passará a ser o chão comum ou locus, do qual partirão as perspectivas éticas da segunda metade do século $\mathrm{XX}$, por isso que nós temos por exemplo, o princípio responsabilidade com Hans Jonas, a ética da espécie com Jürgen Habermas, a ética das virtudes com Alaisder MacIntyre, a ética da autenticidade com Charles Taylor, dentre outras.

Essa problemática referente à moralidade nos posiciona diante de duas possibilidades: permaneceremos trabalhando com tais conteúdos? Ou lançaremos esforços na tentativa de construção de uma nova perspectiva moral que possa dar conta dos problemas atuais?

O crescimento demográfico exacerbado acirra os problemas referentes ao contexto das relações humanas e das nossas relações com o mundo. Por exemplo, o aumento excessivo da exploração de recursos naturais que hoje já coloca no horizonte da espécie humana o perigo da extinção. Tais recursos não são recursos infinitos, estão se tornando escassos, e a sociedade munida de uma economia brutal, marcada pelo neoliberalismo como forma agressiva de avanço do capitalismo, as pessoas são postas em uma condição de sub-humanidade, são destituídos de suas potencialidades emancipatórias e suas potencialidades reflexivas levando a uma exploração do indivíduo, a uma despersonalização e a uma autodestruição com ares de uma experiência estética de primeiro grau, como afirma Walter Benjamin. O gozo do consumismo cria essa falsa impressão de que estejamos vivendo uma experiência estética, quando no fundo estamos vivendo é a nossa própria autoexploração e autodestruição. Estas são questões que nos imprimem uma necessidade de repensar a moralidade no contexto da sociedade da civilização tecnológica.

De ambos os lados existem perigos. De um lado, suspeitamos que a manutenção daqueles conteúdos arcaicos de moralidade não se apresenta de forma satisfatória, pois os mesmos não dão conta das formas de vida contemporânea; por outro lado, teremos graves problemas se 
abandonarmos esses conteúdos sem critério algum, corremos um risco de perder definitivamente a vinculação social. As religiões já não conseguem fornecer vínculos de coesão e solidariedade social, e acabam entrando como elementos potencializadores e aceleradores de conflitos no século XX.

\section{ANTROPOLOGIA NORMATIVA, HERMENÊUTICA E RESPONSABILIDADE}

As proposições éticas da segunda metade do século XX são um estímulo a uma Antropologia Normativa, uma possibilidade de reposicionar o humano como um ponto crucial da reflexão moral, no qual ele possa ter critérios para decidir sobre suas ações e conviver com o diferente, conviver com o espaço democrático da esfera pública. Neste sentido resta-nos pensar sobre que tipo de moralidade nós vamos estimular ou vamos construir. Seria possível a construção de novos pressupostos ou novos conteúdos morais e normativos para a civilização tecnológica?

A relação entre o fazer técnico e científico e sua vinculação, ou afinamento com os conteúdos ético-morais continua sendo um dos maiores desafios à Filosofia Prática contemporânea. Os avanços das tecnociências no século passado produziram um sentimento de que os conteúdos éticos e morais estavam em relação diametralmente oposta à tais avanços, o que direcionou-se para uma estruturação tecnocientífica enquanto tecnocracia, e também para uma deflação dos conteúdos redescricionais do sujeito, que ao mesmo em que é transformado em informação, em um pacote de dados - desde sua história social até os âmbitos mais recônditos de sua existência (genética), é alijado do processo de interpretação destes dados, não compreende a si mesmo e tampouco ao mundo em turbilhão que se apresenta e do qual participa automática e mecanicamente. Este processo de alijamento reabilita o conceito moderno de menoridade [Unmündigkeit] que

[...] ganha um peso gritante na contemporaneidade, na qual o sujeito é transformado gradualmente em "presa" de uma biotécnica e de um mercado violento, para os quais é despersonalizado e transcrito como apenas um conjunto ou banco de informações (Glässerner Mensch). Menoridade agora se traduz sob o signo psíquico-libidinal e mercadológico de uma reificação autoimposta (FERNANDES, 2018, p. 132).

Assim, uma Antropologia Normativa e Hermenêutica, possui um aspecto fundamental no momento em que coloca para o sujeito a possibilidade de retomar os potenciais emancipatórios e de autonomia que possibilitem uma redescrição de si mesmo e do mundo, estamos diante de um horizonte que é marcado por estes impulsos redescricionais.

O monopólio das ciências hoje, não é o monopólio da ciência ou da técnica titânicas tal qual entre os séculos XIX e XX, mas o monopólio de uma ciência rededescricional, no sentido de 
se definir quem pode redescrever o ser humano e o mundo - no caso as ciências biomédicas, talvez no sentido heideggeriano, de transformar estes em uma imagem, como uma linguagem.

Este é o problema ao qual chegamos e ao qual torna-se preciso refletir: Não se trata da redescrição do mundo ou a redescrição do humano, pois isto é um fato que figura como um caráter destinal, utilizando aqui um termo heideggeriano; mas o problema é quando o sujeito não consegue se redescrever e não tem possibilidades emancipatórias e redescricionais para se compreender e se colocar diante do mundo.

Neste sentido, o problema reside na possibilidade do sujeito retomar as rédeas desse processo redescricional, de poder participar, desta forma, das decisões e do direcionamento sobre a tecnologia e sobre a ciência, e não permanecer de forma apática e passiva, transferindo a determinados grupos de experts uma decisão sobre estes conteúdos que caberia a si mesmo.

É preciso uma participação ativa do sujeito nesse processo redescricional, e uma Antropologia Normativa foge aos critérios da deontologia, voltando a arraigar no sujeito esses potenciais redescricionais e isto seria uma das contribuições mais expressivas da Hermenêutica para a criação de pressupostos morais para a civilização tecnológica.

A possibilidade de poder projetar uma vida não fracassada, não reificada, acaba por abrir o caminho para uma tomada de responsabilidade do sujeito, ancorada na autocompreensão ética deste enquanto indivíduo autônomo e moral. Como passo posterior podemos nos dirigir ao que Habermas (2004) compreende como uma moralização da naturez̧a bumana, no sentido kantiano do indivíduo poder se inserir no contexto discursivo igualitário e poder, a partir de conteúdos morais, tornar indisponível aquilo que a tecnociência moveu para o campo da disponibilidade técnica.

Qualquer itinerário para uma nova moralidade ou para uma transformação dos conteúdos já existentes passará pela retomada e recolocação do homem neste processo, sua centralização como protagonista e partícipe no âmbito de assunção da responsabilidade. Nesse sentido. Há uma relação entre a Antropologia Normativa e a Hermenêutica que coloca novamente o pressuposto da responsabilidade como central no modo de existência nas sociedades contemporâneas.

A Hermenêutica possui uma contribuição ímpar no processo de vertebração de uma Antropologia Normativa ao instaurar um campo de reflexão em constante redescrição, reavaliação, compreensão e interpretação de si e do mundo, da ciência, das relações e ações humanas; em suma, como aponta Gadamer (1993), abrindo as potencialidades da própria práxis, e também sendo este modo de ser, viver, relacionar-se.

Retomando o conceito de responsabilidade, temos duas possibilidades muito ricas: a primeira no nível do sujeito, ou seja, na medida em que o sujeito consegue se redescrever, consegue ter acesso aos pressupostos básicos da interpretação de si mesmo e do mundo, consegue ter acesso 
a âmbitos decisórios acerca de sua própria vida. E não mais imputa a outros a autonomia para decidirem sobre estes pontos; já no campo da ciência, a questão da retomada da responsabilidade sobre o fazer científico poderia refrear os impulsos de uma ciência voltada para o mercado e também arrefecer o cerne endurecido da ciência direcionado para uma tentativa de redescrever de forma determinista e reducionista a experiência humana.

Temos assim, dois grandes campos pela frente, duas perspectivas que se abrem a partir do momento em que a relação entre Hermenêutica é Antropologia Normativa fornecem para o sujeito os elementos para que ele possa pensar a si mesmo, para que consiga aproximar-se de uma compreensão muito mais profunda acerca de si mesmo e acerca do mundo. Esta relação entre Antropologia Normativa e Hermenêutica pode fornecer elementos uma construção de um conceito de subjetividade muito mais profundo, e nesse sentido, ocorre uma redescrição do sujeito e ao mesmo tempo uma redescrição do mundo, e do modo como compreendemos e nos relacionamos com tal, a partir de uma linguagem específica que é a linguagem da ciência.

\section{CONSIDERAÇÕES FINAIS}

Procuramos aqui expor, em linhas gerais, um quadro da sociedade tecnológica do século XX e início do século XXI, procurando apontar a forma como os avanços tecnológicos acirram o nosso modo de compreensão moral, porém, salientando, sobretudo, que o problema não reside na tecnologia em si, mas em problemas estritamente humanos, que nos acompanham no decorrer de nossa trajetória evolutiva e que são acirrados pelos avanços da tecnologia.

Foi esboçado um cenário no qual compreende-se nossos conteúdos morais como resultado de impulsos muito antigos dentro de nossa trajetória evolutiva, e acirrados a partir do século XX em decorrência dos avanços tecnocientíficos. Tais avanços potencializam nossa relação moral expondo uma defasagem dos mesmos em relação à forma de vida de uma civilização tecnológica.

A questão que nos resta é compreender de que forma vamos buscar uma resolução para o problema da moralidade e as aporias decorrentes de tal. Vamos continuar em trânsito com um conjunto de conteúdos morais oriundos de uma outra época, ou vamos lançar esforços para reestruturar esses conteúdos ou construir novos conteúdos que possam estar alinhados às exigências da forma de vida contemporânea? Terminamos apontando que uma das possibilidades é a retomada da responsabilidade propiciada pela relação entre Hermenêutica e Antropologia Normativa.

A Hermenêutica pode contribuir para uma elucidação e mesmo desvelamento de uma compreensão de subjetividade mais profunda na qual o sujeito possa apropriar-se dos potenciais redescricionais; aqui os estímulos concentram-se em uma Antropologia Normativa, não 
essencialista, e sempre dinâmica. No âmbito da ciência e da técnica, uma retomada da responsabilidade dos sujeitos, pode promover maior interação e participação tanto nos direcionamentos destes, quanto na regulação das intervenções tecnocientíficas sobre o mundo e sobre a natureza humana.

Porém, ainda resta-nos o questionamento inicial como uma divisa aberta na tessitura de nossa práxis reflexiva contemporânea: vamos manter os mesmos conteúdos morais que nos acompanharam até aqui? Ou lançaremos esforços na construção de outras formas, e outros possíveis contributos para a manutenção dos vínculos de coesão social. Como uma janela aberta, esta questão permanece nos chamando a atenção em nossa contemporaneidade e se espraia por vários campos. O primeiro passo neste itinerário, de forma preliminar, apresentado aqui, reside na possibilidade de se reforçar os conteúdos de uma Antropologia Normativa a partir de uma interação com a Hermenêutica, tendo como centro o conceito de responsabilidade.

\section{REFERÊNCIAS}

CLOTET, J. (Org.). Bioética. Porto Alegre: EDIPUCRS, 2012.

FERNANDES, M. Sobre o conceito de técnica em Jürgen Habermas: Traços de uma Filosofia da Tecnologia. 2018. 190 f. Tese (Doutorado em Filosofia) - Escola de Humanidades - Faculdade de Filosofia, Universidade do Vale do Rio dos Sinos (UNISINOS), São Leopoldo, 2018.

FERRATER MORA, J. Sobre la sociedad contemporanea: Técnica y civilización.

Revista Realidad, v. 2 (nº. 6., Noviembre-Diciembre), 1947, pp. 366-376.

GADAMER, H-G. Wahrheit und Methode: Ergänzungen; Register. 2. ed. GesammelteWerke, Bd. 2. Tübingen: Mohr Siebeck, 1993.

HABERMAS, J. O futuro da natureza humana: A caminho de uma engenia liberal? Trad. Karina Jannini. São Paulo: Martins Fontes, 2004.

JONAS, J. Das Prinzip Verantwortung. Frankfurt am Main: Suhrkamp, 1984.

KOLATA, G. Scientist reports first cloning ever of adult mammal. In: The New York Times. 23 fev. 1997.

MAX-PLANCK-GESELLSCHAFT. Scientists unite for peace. The Göttingen Manifesto against nuclear weapons: 1957. [S.1.], 2018. Disponível em:

< https://www.mpg.de/955826/13 event8-1957>. Acesso em: 07 jun. 2018.

PIZZI, J. Ética do Discurso: A racionalidade ético-comunicativa. Porto Alegre: EDIPUCRS, 1996. 
WILSON, E. O. Altruism and the New Enlightenment. An Interview with E. O. Wilson. In: Slate. April 30, 2012. Disponível em: https://slate.com/technology/2012/04/e-o-wilson-onaltruism-and-the-new-enlightenment.html. Acesso em: 25/08/2019. 